\title{
Schools as partners in creating a learning city
}

\author{
Mike Kendall \\ Birmingham City Council Education IT Service, Martineau Centre, Harborne, B32 2EH, \\ UK Mike_Kendall@birmingham.gov.uk
}

Keywords: learning, content, teachers, community, partnership

\begin{abstract}
The development of the Birmingham Grid for Learning is the largest schools ICT infrastructure project in the UK. The programme seeks to transform the school system, the role of teachers and to be an agent in the realisation of Birmingham's ambition to be a learning city. The underlying model for the organisation of the programme is to create and manage a creative tension between the people, content and opportunity within a learning gestalt, recognising an inner strength in its connectedness to a wide range of social and political as well as educational initiatives.
\end{abstract}

\section{WHAT IS THE BIRMINGHAM GRID FOR LEARNING?}

The Birmingham Grid for Learning (BGfL) is part of Birmingham's programme to realise its education vision and strategy. It is a partnership bringing together the energies of the Local Authority's Education Service, schools and communities with public and private sector partners to accelerate the realisation of the school of the future as the hub of a connected networked community. The Birmingham Grid for Learning provides the opportunity to ensure all Birmingham City Council schools are equipped to achieve an established level of information and communications technology, as defined in the Success for Everyone Standards for ICT (Birmingham City Council 1997).

The BGfL builds upon a momentum for the application of ICT to learning and the management of learning established through the work of innovative schools and the Education Department's school improvement programmes. The mutually supportive developments have included: the innovative use of government grants; the development of integrated learning 
systems; the effective use of management information systems to support school decision making; the production of IT Guidelines; the Year of IT in 1996; and the School of the Future Conference in 1997. The climate in Birmingham created by the Chief Education Officer, Professor Tim Brighouse, has supported risk taking with his belief in the transformative capacity of ICT.

The BGfL is, in the first instance, a four-year programme to be achieved with additional funding from the Department for Education and Employment NGfL Standards Fund Grant (DfEE 1997a and 1998) and the National Lottery New Opportunities Fund (DCMS 1998), complementing planned expenditure by schools and the City Council. The BGfL is one of 10 Pathfinder NGfL projects in the UK. The National Grid for Learning is the UK Government's ICT Strategy for educational infrastructure and content (DfEE, 1997b), a part of the Blair government's vision for '...transforming education' (COI 1998).

The BGfL aims to:

1. provide ready access through which teachers, pupils and the wider education community will be able to access and contribute to a rich diversity of local, national and global learning opportunities (such access will be supported from many points in the community, not just schools, and will be a 24-hour, 365-day service);

2. ensure that all teachers and support staff have the opportunity to become confident and competent to make the appropriate use of ICT for the teaching, learning and the management of learning;

3. provide pupils with the opportunity to accelerate and enhance their opportunities for learning;

4. support schools to extend their roles as centres of learning for their communities;

5. be achieved in partnership with the schools and their communities, as well as public and private sector organisations.

\section{THE EMERGING REALITY FOR SCHOOLS}

This significant change initiative will impact most visibly on school ICT infrastructure with the provision of whole school networks and high-speed connectivity though the schools Intranet, with all 480 schools connected by August 1999 and internally networked by December 2001 .

It is clear that many schools initially see the benefits in terms of more technology, to continue with, even accelerating their current school development plan, and to remove a financial worry. The 89 pilot schools in 1998-99 quickly realised the overall strategy was very different, and they could not just pull out their shopping list of computers; they had to review 
their overall school development strategy. They had to produce a whole school ICT development plan that addressed the collaborative and shared goals of the BGfL, including a vision statement taking a 3-5 year view of their learning and curriculum development in the school and for the community, including their curriculum and school management ICT systems.

As the programme progresses so are the demands upon schools, with an increasing emphasis upon the schools' capacity to make decisions and to manage change, ensuring processes for continuous change are created, connecting all initiatives currently underway; ICT cannot be a 'bolt-on'. The purchase of computers is usually viewed as a discrete activity and localised in its impact within the school. BGfL is a whole school strategy bringing together changes to learning and the management of learning systems, affecting all the staff and pupils at one time. The emerging reality can be constrained by the '... walls of the mind' (BCS 1998).

The first 89 schools are being established to provide professional support to other local schools as local support centres distributed across 39 electoral wards, as well as becoming Centres of Expertise, using the Birmingham Grid to pooling expertise, making readily accessible and locally owned.

\section{DEVELOPING THE CENTRES OF EXPERTISE AND LOCAL SUPPORT CENTRES}

The establishment of Centres of Expertise is a key element in the development of the BGfL as schools become centres of networked learning communities and Local Support Centres with teachers readily working together.

The concept of the Centre of Expertise is being developed with the 89 schools receiving intensive support this year. The development is at an early stage with schools meeting again in January 1999 when their infrastructure and Grid connectivity has been established, although some have already started working together. Each of the 89 schools identified an area in which they already had expertise that they could make accessible through the Grid, or could develop once they had received their targeted support.

The Centres of Expertise are developing to:

1. ensure a shared understanding of mutual accountabilities and responsibilities;

2. develop the role of the Local Support Centre;

3. ensure diversity amongst the Centres of Expertise proposals;

4. subject individual centres to peer review/moderation;

5. identify shared professional development needs. 
The 89 schools are just the first. All schools have a wealth of expertise that they make accessible to other colleagues and communities. The Centres of Expertise will be developing working methods to make the collaborative working possible. This is a new initiative, with no one having developed a Grid like this before, so the schools and Education Service are all learning together. In time, other non-school Centres of Expertise will be part of the Grid, for example, the local community library and museum.

Traditionally in the UK, schools and their communities had been isolated from their peers, only being accessible as and when special conditions apply, such as inspections and one-off opportunities. The development of the school inspection system and the publication of school examination results in league tables have increased the accountability of schools, as have the perceptions in society that schools had been failing, some if not all of their pupils. It had not been a lack of information about different approaches to learning, or the need to develop a founded rationale for school improvement, it had been its accessibility. Many schools had been isolated, their experiences had been isolating, and the majority of teachers had not had a structured opportunity to ongoing professional development and reflection.

The development of the BGfL is founded on the idea of creating a learning gestalt, whereby all schools are actively working together, sharing the risks and benefits of school improvement initiatives, such that all improve and celebrate their expertise. The approach is founded on the belief that all schools and teachers have areas of expertise that others can learn from, readily supporting each other. Just observe any group of teachers together and they quickly share anecdote and founded theory on this and that. However, many obstacles exist in providing all teachers with regular opportunities to engage in such activities. The BGfL hypothesis is that if all schools are connected, they provide a means for a regular and readily accessible dialogue. It is on this basis the idea of mutual accountability is being tested.

The Centres of Expertise are not purely founded on teachers; they want to recognise the expertise available within communities of the school, whether this is the parents, pupils, support staff, or any other group. They are seen as partners in the establishment of a learning city recognising the broadly based social and economic capital and potential of Birmingham and the wider world.

\section{BGFL AND THE CHANGING ROLE OF THE TEACHER}

The BGfL raises a number of key strategic challenges for schools and the teaching staff that can be broadly summarised in the working model 
developed for its implementation. BGfL is based on the premise of developing the people, content and opportunity which together produce a creative environment that can be utilised to develop Birmingham's schools as centres of connected learning communities, as partners of a learning city (see Figure 1). The working model builds on Child's (1987) work on the strategic challenges facing large organisations, adapted by Kendall (1997) in an analysis of ICT innovation risks for Birmingham.

In describing a working model it provided an approach to the overall development strategy and the way they were interdependent, informing the creation of teams of people to work on the development and to provide a coherent sense of purpose.

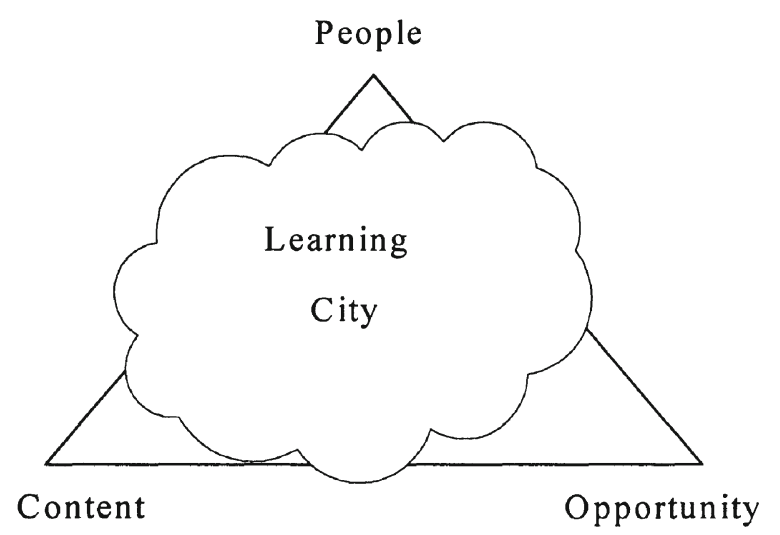

Figure 1. BGfL Development Strategy Model

People: the people who can contribute to and learn via the BGfL will be able to work together, enhancing face-to-face networks, and creating new networks enabled and enhanced by the communications technology. This should include email, bulletin boards, and conferencing, making use of text, voice and image.

Content: the content to enhance the communication potential and opportunity for people, as well as creating new opportunities. We are all content providers, teachers, pupils and the wider community, with knowledge, skills and experiences we can share with others. Commercial content providers will also play a significant role as the creators, publishers and channel of a varied range of resources.

Opportunity: to be able to take advantage of the growing networks of people with whom we share a common interest and need:

"... multiplying the energy to reach a critical mass of change which will fission out to all schools." Tim Brighouse 27 February 1997. 
And to access and contribute to the growing range of content, access opportunities will be required. People, need the opportunity to access content. Initially this has meant providing the technical infrastructure: this is not enough. The ready availability of the technology, will not, of itself, transform the opportunity to access people and content to support their own learning needs and wants. It will be essential that a wide range of structural changes take place, not least for teachers.

Teachers are central to achieving the creative learning community in schools founded in the themes of people, content and opportunity.

\subsection{People}

The nature of the relationship with teachers in the networked school will change from traditional teaching, people, as learners will be central.

"The system is focused on how the teacher can do his/her job, rather than on how the students can do theirs, namely to learn. The teacher's first (false) assumption must be that all 30 students are equally interested, ready and willing to learn some specific bit of knowledge that the teacher chooses to pass on before the bell rings for the next group of students to arrive." (Jaeger 1998)

Whilst this quote can be criticised as taking an extreme position, the basic premise is widely recognised, it is based on mass teaching of a standard curriculum. It is based on the teacher knowing the answers and channelling the development of the students.

The people who are central to the development of the BGfL are the learners, whether this is the student in the school, or the teachers and other school staff. It is about the notion that the school will provide an environment in which learners are able to access co-learners and learning guides, who understand how to support people learning. In Birmingham, which has promoted multi-faceted, ipsative rather than normative, generalist approaches to learning, this will be very much in-line with the preferred learning styles of the learner, building on Gardner's (1983) multiple intelligences.

Jaeger (1998) proposes a new school system, whose key elements "... must treat students as learning individuals ... where each student plays an active role ... the opportunity for interaction and joint work ... [and] accessible to all students who show motivation and the desire to learn."

The challenge for the BGfL is to build the capacity in people to be able to gain optimally from their learning environment, whether it is in the confines of the classroom or the global village. This will require the recognition that learner and manager of learner is interchangeable, and that 
at times the traditional student-teacher relationship can be reversed, for the better.

\subsection{Content}

What is it that people communicate about? This is the premise of teaching and learning, somebody can help somebody to a new understanding and capacity that they didn't have or couldn't express before. This is the content. It can be formal or informal. The question is who provides the content.

Teachers regularly produce content, it is their trade, the presentation of which is their craft skill, weaving an alchemy that engages young people in their learning. However, this content is constrained in traditional teaching by those resources that are readily available, and support the taught curriculum. In the connected learning environment a seemingly limitless resource is available, however unstructured and inaccessible for the learner and teacher.

The teacher as 'content' manager and creator is fundamental to the creation of the Birmingham Grid. Providing the reason why people communicate and learn, and to create more learning content themselves. Content production is a time intensive activity for teachers as is content management: why not use the Birmingham Grid to work with other teachers, educators and learners, as well as community and commercial content providers to avoid duplication and wasted energy.

\subsection{Opportunity}

Schools have provided the opportunity to access people and content in a tightly structured environment, with clearly defined rules to manage the learner and learning process. The BGfL aims to extend the opportunity for learners to access learning beyond the traditional structures of learning.

One of the key targets is to provide all schools with the technological infrastructure of a connected networked community, obliging people to use it effectively developing new approaches to learning. BGfL must be part of a wider movement to transform education, whether as a National Government or as a local initiative. In the UK the National Grid for Learning is a part of the Government's information society initiative, of which the BGfL is a constituent part.

No matter how many initiatives are planned, launched and even implemented, unless they are part of a fundamental appraisal of learning and its objectives in the learners' locality, transformation in learning will not happen. 


\section{THE LEARNING CITY - CREATING THE CONDITIONS FOR LEARNING REGENERATION IN SCHOOLS}

The BGfL is seeking to create a set of conditions that, it believes, will support the transformation of education in Birmingham. However, this belief needs to set in the broader context in which schools provide a service, learners learn and communities are developed. Birmingham aspires to become a learning city, in which schools and their communities will have a critical role.

"A Learning City is one which strives to learn how to renew itself in a period of extraordinary global change. The rapid spread of new technologies presents considerable opportunities for countries and regions to benefit from the transfer of new knowledge and ideas across national boundaries." (DfEE 1998a)

"A true learning (community) is one which develops by learning from its experiences and those others. It is a place which understands itself and reflects upon that understanding ... the learning (community) is creative in its understanding of its own situation and wider relationships developing new solutions to new problems." (Landry and Matarasso 1998, in DfEE 1998a)

Fundamentally, schools must be part of a true learning community, a task challenged with the growth of information and communications technology and its impact on learning.

It is fundamental to the development of the BGfL that schools are learning institutions, as opposed to teaching institutions. The school must be connected to its local communities as active partners, rather than as service providers, through this process connecting teachers to their local communities. Schools have always operated as part of a continuum of lifelong learning, but unconnected. As active partners in a learning city they must recognise they are active partners in the task of social and economic regeneration.

Birmingham is establishing two Education Action Zones, areas of social and economic, as well learning, distress to provide the conditions for regeneration, focused around schools. The 6 principles of the Zones are, "... a multi-agency drive ... a radical redefinition of how schools function ... innovative practice and seeks to extend it ... emphasis[ing] inclusive practices ... promotes lifelong learning ... to share good practice ..." (Birmingham City Council 1998). In this redefined world, schools have been provided with a test-bed for innovative new ideas, where the rules that confine the majority of schools to respond to the needs of their communities 
as they seek to transform themselves, can be dis-applied. An exciting educational initiative to accelerate another exciting educational initiative, the BGfL.

\section{CONCLUSION}

I have sought to provide an overview of developments in Birmingham as schools become part of a connected learning community and the challenges faced transforming this change programme from a technological initiative into a learning revolution.

The planned transformation of the teachers' and schools role is creating a backlash, with a questioning of the planned levels of expenditure, the training demands upon teachers and its negative effect on children, 'Computers can't teach children how to think' (Williams 1999).

It is early days; the BGfL development only started in April 1998, the Education Action Zones started in January 1999. Many challenges are being faced the transformation has begun. This is the start of a journey, the ambitions are considerable, all stages are not clear. It is essential that a dialogue is maintained with all stakeholders, especially teachers, the uncertainty is unsettling and recidivist. All I can say I am glad I am on this journey and I want to share this excitement and the opportunity with as many people as possible, after all Birmingham is doing what we all have to do to survive and thrive.

Birmingham is not operating in isolation, it is part of the global transformation of education accelerated, or even predicated on the explosion of opportunity through information and communications technology. It is essential for Birmingham that a dialogue is developed, so that Birmingham learns from the global community as it develops it schools, teachers and learning communities.

\section{REFERENCES}

Birmingham City Council (1997) IT Guarantee and Success for Everyone. UK: Birmingham Education Department.

Birmingham City Council (1998) Birmingham Education Action Zones. UK: Birmingham Education Department.

BCS (1998) 2000 and Beyond: A School Odyssey. UK: British Computer Society.

Child, J. (1987) Information technology, organisation, and the response to strategic challenges. California Management Review Fall 1987, 33-50.

COI (1998) Our Information Age: The Government's Vision. London: Central Office of Information.

DCMS. (1997) The People's Lottery. London: Her Majesty's Stationery Office.

DfEE (1997a) The Standards Fund 1999-2000. DfEE circular number 13/97, London:

Department for Education and Employment. 
DfEE. (1997b) Connecting the Learning Society. A Consultation Paper. London: Department for Education and Employment.

DfEE (1998a) Practice, Progress and Value Learning Communities: Assessing the Value. London: Department for Education and Employment.

DfEE (1998b) The Standards Fund 1999-2000. DfEE circular number 13/98, London: Department for Education and Employment.

Gardiner, H. (1983) Frames of Mind: The Theory of Multiple Intelligences. New York: Basic Books.

Jaeger, K (1998) A New School System: The Jay System. Bath, UK: International School of America (Bath).

Kendall, M. (1997) ICT Innovation in Birmingham City Council Education Department. MBA Project, Birmingham University, UK.

Williams, R. (1998) Computers can't teach children to think. Times Educational Supplement $12^{\text {th }}$ February 99.

\section{BIOGRAPHY}

Mike Kendall, a teacher of Design and Technology, works on innovative educational development programmes for Birmingham City Council, with responsibility for a range of ICT learning development programmes, including the BGfL. His $\mathrm{PhD}$ research focuses upon the roles of ICTs in enabling connected learning communities to develop and to become selfsupporting. 